Esperanza Merino'

Adelina Gimeno ${ }^{2}$

Mar Alcalde ${ }^{3}$

Javier Coy²

Vicente Boix ${ }^{1}$

Carmen Molina-Pardines ${ }^{2}$

Maria Paz Ventero ${ }^{2}$

Antonio Galiana ${ }^{4}$

Elena Caro ${ }^{1}$

Juan Carlos Rodríguez ${ }^{2}$

\section{Impact of Sepsis Flow Chip, a novelty fast microbiology method, in the treatment of bacteremia caused by Gram-negative bacilli}

\begin{abstract}
'Department of Infectious diseases, General University Hospital of Alicante-ISABIAL, Spain. ${ }^{2}$ Department of Microbiology, General University Hospital of Alicante-ISABIAL, Spain.

${ }^{3}$ Department of Infectious Diseases, Hospital Universitario Santa Lucia, Cartagena, Murcia

${ }^{4}$ Department of Microbiology, FISABIO, General University Hospital of Elche. Elche, Spain.
\end{abstract}

Article history

Received: 21 September 2020; Revision Requested: 26 December 2020; Revision Received: 21 January 2021; Accepted: 27 January 2021; Published: 23 March 2021

\begin{abstract}
Objective. The aim of this study was to assess the impact of the information provided by the new Sepsis Chip Flow system (SFC) and other fast microbiological techniques on the selection of the appropriate antimicrobial treatment by the clinical researchers of an antimicrobial stewardship team.
\end{abstract}

Methods. Two experienced clinical researchers performed the theoretical exercise of independently selecting the treatment for patients diagnosed by bacteremia due to bacilli gram negative (BGN). At first, the clinicians had only available the clinical characteristics of 74 real patients. Sequentially, information regarding the Gram stain, MALDI-TOF, and SFC from Vitro were provided. Initially, the researchers prescribed an antimicrobial therapy based on the clinical data, later these data were complementing with information from microbiological techniques, and the clinicians made their decisions again.

Results. The data provided by the Gram stain reduced the number of patients prescribed with combined treatments (for clinician 1, from 23 to 7, and for clinician 2, from 28 to 12), but the use of carbapenems remained constant. In line with this, the data obtained by the MALDI-TOF also decreased the combined treatment, and the use of carbapenems remained unchanged. By contrast, the data on antimicrobial resistance provided by the SFC reduced the carbapenems treatment.

Conclusions. From the theoretical model the Gram stain and the MALDI-TOF results achieved a reduction in the combined treatment. However, the new system tested (SFC), due to the resistance mechanism data provided, not only reduced the combined treatment, it also decreased the prescription of the carbapenems.

Key words: Bloodstream infection, MALDI-TOF, Sepsis Chip Flow, gram negative bacilli.

\section{Correspondence:}

Carmen Molina Pardines

Department of Microbiology, General University Hospital of Alicante-ISABIAL, Spain.

C/Pintor Baeza, 12. CP:03010

E-mail: carmenmolinapardines@gmail.com
Impacto de Sepsis Flow Chip, un método microbiológico novedoso y rápido, en el tratamiento de la bacteriemia causada por bacilos gramnegativos

\section{RESUMEN}

Objetivo. Nuestro trabajo trata de aportar información sobre el impacto del nuevo sistema Sepsis Chip Flow system (SFC) y otras técnicas de diagnóstico microbiológico rápido en la selección del tratamiento antibiótico apropiado por el equipo de infectólogos dentro de un grupo multidisciplinar PROA.

Método. Dos infectólogos con amplia experiencia clínica llevan a cabo un ejercicio teórico de forma independiente seleccionando los tratamientos de los pacientes diagnosticados de bacteriemia por bacilos gramnegativos. En primer lugar, los infectólogos solo tienen acceso a los datos reales de 74 pacientes. Secuencialmente, se les aporta información de los resultados de la tinción de Gram, MALDI-TOF y SFC (Vitro). Inicialmente, los infectólogos prescriben un tratamiento antibiótico en base a los datos clínicos y más tarde, van modificando los tratamientos en base a la información microbiológica recibida.

Resultados. Los datos aportados por la tinción de Gram reducen el número de pacientes pautados con tratamientos combinados (para el clínico 1, de 23 a 7, y en el clínico 2, de 28 a 12), pero el uso de carbapenémicos permanece constante. En la misma línea, los datos aportados por MALDI-TOF también disminuyen el número de tratamientos antibióticos combinados aunque sigue sin modificarse el número de tratamientos con carbapenémicos. Por contra, los datos de resistencia antibiótica aportados por SFC reducen el número de tratamientos con carbapenémicos.

Conclusiones. A partir del modelo teórico, la tinción de Gram y los resultados de MALDI-TOF Iograron una reducción en el tratamiento combinado. Sin embargo, el nuevo sistema probado (SFC), debido a los datos de mecanismos de resistencia proporcionados, no solo redujo el tratamiento combinado sino que también disminuyó la prescripción de los carbapenémicos.

Palabras clave: Bacteremia, MALDI-TOF, Sepsis Chip Flow, bacilos gramnegativos. 


\section{INTRODUCTION}

Bloodstream infections (BSI), also called bacteremia, are associated with high rates of morbidity and mortality. The microbiological identification of the causative pathogens is crucial for optimal management. Therefore, a faster identification of the microorganisms causing the bacteremia could enable the appropriate species-specific therapy to be started earlier, thereby improving patient outcome and reducing the potential development of resistance and possible side effects $[1,2]$.

Today, the treatment of Gram-negative bacilli (GNB)-BSI is particularly complicated due to the high rates of resistance from multiple resistance mechanisms, opening up only limited treatment options. Furthermore, due to the emergence of multi-drug resistant (MDR) GNB, early targeted treatment is key for both avoiding of broad-spectrum antimicrobials and ensuring the correct treatment of the pathogen. On the other hand, the cautious administration of the antimicrobials performed by the antimicrobial stewardship team (AST) helps to prevent the development of antimicrobial resistance over the long term [3].

Integrating the fast diagnostic laboratory techniques with AST has been demonstrated to +improve patient outcome compared to the standard microbiology reporting [4]. In fact, it is evident that the development of the MALDI-TOF provides timely and accurate identification of the organism, and when combined with the AST it can shorten the length of the hospital stay and the costs for the treatment of the GNB-BSI. However, the MALDITOF does not provide information regarding resistance [5].

The Sepsis Flow Chip (SFC, Master Diagnostica) assay is a recent developed and commercialized system based on a multiplex PCR. SFC provide an automated molecular diagnostic test for the identification of the genus, species and genetic resistance determinants for a broad panel of the commonest GNB organisms isolated from blood cultures. It has an approximate turn-around time of 4 hours from the positive blood cultures. The assay can detect at the genus/species level 12 bacteria and 1 yeast (Streptococcus pneumoniae, Streptococcus agalactiae, Streptococcus spp., Staphylococcus aureus, Staphylococcus spp., Enterococcus spp., Listeria monocytogenes, Stenotrophomonas maltophilia, Serratia marcescens, Escherichia coli, Klebsiella pneumoniae, Morganella morganii, Proteus spp., Acinetobacter baumannii, Pseudomonas aeruginosa, Neisseria meningitidis and Candida albicans; also It detects the generic category "Enterobacteriaceae". SFC assay detects the most important genetic resistance determinants involved in resistance to methicillin and vancomycin in Gram-positive pathogens and determinants related to beta-lactam resistance mechanisms such as ESBLs and carbapenemase production in Gramnegative bacteria (mecA, vanA/B, blacTX, blaSHV, blaSME, blaKPC, blaNMC/IMI, blaGES, blaIMP, blaGIM, blaVIM, blaSPM, blaSIM, blaNDM, blaOXA-23, blaOXA-24, blaOXA-48, blaOXA-51 and blaOXA-58.)

This test has been recently demonstrated to have a high sensitivity and specificity for organism and resistance identification [6]. However, the impact of SFC results on the management of BGN-BSI has not been analyzed yet, due to this system has been recent commercialized.

The purpose of this study was to evaluate the impact of the identification and resistance data provided by SFC, as a complement of MALDI-TOF information, on the antimicrobial therapy prescribed by the AST. The evaluation was performed on a theoretical model generated from clinical patient data, in order to avoid the variability presents in the clinical routine.

\section{MATERIAL AND METHODS}

Study location and design. This single-center study was conducted at the General University Hospital of Alicante (Spain), a 780-bed tertiary hospital.

In this study, 74 consecutive patients were included in a retrospective manner. All the patients were above the age of 18 years and experiencing the first episode of GNB bacteremia (mono or polymicrobial BSI). This study was performed under the written authorization of the CEIm (Ethic Committee of research with drugs) with implementation of the national legal standards and the guidelines established in the Declaration of Helsinki (2000). Data on the demographic characteristics, comorbid status (Charlston index), clinical signs and symptoms of infections, severity of illness (Pitt score), immunosuppressive therapy and microbiology results were collected from each patient. Also, the infection-related characteristics of the infection source (according to the definitions published by CDC) were included. Details of the syndromes and clinical characteristics of the patients are available as supplementary data (S1).

The clinical data obtained were anonymized. Information on the epidemiology of the infectious process and the prescribed antimicrobial therapy was removed before providing the clinical data to the clinical researchers who conducted this study.

Microbiological tests. Microbiological results provided to clinical researchers were obtained as a part of the clinical routine when the infectious process occurred, following these protocols:

All the blood samples obtained were subjected to identical processing methods using the BACTEC automated blood cultures system (BD diagnostics), and standard aerobic and anaerobic blood cultures media. The specimens were Gram-stained when the blood culture bottle showed up as positive. They were analyzed by the MALDI-TOF (Bruker, Germany) for routine identification, and then for a new identification process and detecting resistance mechanisms by SFC.

In addition, positive blood culture specimens were inoculated on the appropriate solid agar media and subsequently identified using the conventional clinical microbiology procedures. The antimicrobial susceptibilities were performed with the Microscan (Beckman). Antimicrobial susceptibilities were determined according to the EUCAST guidelines.

Definitions. The BSI onset was defined as the collection 
time of the first blood sample which yielded the study isolate (index blood culture). Treatment was considered active when the infecting organism was susceptible in vitro to at least one prescribed antimicrobial agent. Treatment was considered optimal when the antimicrobial exhibited in vitro activity and targeted the isolated pathogen based on the patients' overall clinical features, and when it was available, it was in line with the current clinical guidelines.

Antimicrobial recommendations were classified as escalation, meaning a change from a narrow spectrum to a broad-spectrum antimicrobial (with one or more antimicrobials), de-escalation or narrowing the coverage to target the isolated organisms, or discontinuing therapy when the antimicrobial treatment was stopped.

Antimicrobial treatment recommendation. To evaluate this technique in several clinical conditions, two skilled clinicians were selected from two different hospitals. One of them, from a tertiary hospital with complex patients (severe immunosuppression, solid transplants, haematological diseases, cancer and complex surgery) and a high incidence of multidrug resistant pathogens; and the other one from a second level hospital, without these characteristics. Both therapies were in line with the clinical guidelines approved by the infectious diseases commission of each hospital.

Theoretical antimicrobial therapy. In order to know the usefulness of these techniques, particularly the SFC which is recent developed and not evaluated in the clinical practice yet, without the variability associated with clinical routines, two clinical researchers specialized in infectious diseases (one from the same hospital, and the other from another General Hospital) prescribed the antimicrobial therapy according to the information available at different levels:

- First, as an empirical therapy, based on the clinical characteristics.

- Second, using the previous data plus Gram-stain report.

- Third, using the previous data plus the information provided by MALDI-TOF.

- Fourth, using the previous data plus SFC data.

- Fifth, or definitive antimicrobial therapy with the full susceptibility test including the culture and the antibiogram.

Statistical analysis. The categorical variables were expressed as counts (percentage). To evaluate the differences between the empirical treatments and the prescribed treatments after the different techniques the chi-square or Fisher's exact test were used. The contrasts were carried out using IBM SPSS Statistics version 22.0 Software, and a $p<0.05$ was necessary to consider significative differences.

\section{RESULTS}

The analysis was performed on 74 patients with BSI, caused by Escherichia coli (38), Klebsiella pneumoniae (9), polymicrobial (8), Klebsiella oxytoca (4), Enterobacter cloacae (3), Proteus mirabilis (2), Stenotrophomonas maltophilia (2), Serratia marc- escens (2), Achromobacter (1), Citrobacter koseri (1), Bacteroides thetaiotaomicron (1), Campylobacter jejuni (1), Acinetobacter baumannii (1) and Pseudomonas aeruginosa (1). Resistance to the third generation cephalosporins was present in 18/74 (24.3\%) and to the carbapenems in 4/74 (5.4\%).

The empirical treatments decided by the researchers, based on the analysis of the patient's data only showed significative differences in the choice of the carbapenems (22 versus $37, p=0.012$ ).

The information provided by the Gram stain was helpful in preventing combined treatments, since the prescription of this type of treatment was significative reduced by the clinician 1 $(p=0.001)$ and clinician $2(p=0.003)$, but it was not helpful in reducing the use of carbapenems. This also occurred after applying the MALDI-TOF data, because the combined treatments were significative decreased ( $p<0.0001$ in both cases), but the prescription for carbapenems remained unchanged (Table 1).

However, the information generated by the SFC, providing data on the antimicrobial susceptibility of the microorganism, produced a decrease in the use of carbapenems (17 and 32 cases, respectively). This reduction was significative in the case of clinician 2 ( $p<0.0001)$ (Table 1).

The agreement concordance between the treatments proposed by the clinical researchers showed significative differences in the use of carbapenems when the treatment was prescribed based on empirical data $(p=0.012)$, gram data $(p=0.001)$, and MALDI-TOFF data $(p=0.005)$. Only, the carbapenems prescription did not show differences after knowing SFC data.

Moreover, the antimicrobial therapies prescribed based on the fast-molecular techniques (MALDITOF plus SFC) were in line with the treatment selected using the culture and antibiogram data, without show significative differences.

On analyzing whether the treatments based on the empirical data were correct, it became evident that in 16.2\% of the cases (researcher 1) and in $10.9 \%$ of the cases (researcher 2) the prescription therapy was inappropriate, because the treatment involved drugs to which the causal agent was resistant. These percentages of inappropriate treatment dropped to 13.8\% (clinician 1) and $8.1 \%$ (clinician 2) using data from the Gram stain, and to $10.8 \%$ (researcher 1) and $4.1 \%$ (researcher 2) using the information from the MALDI-TOF. The highest percentage of correct prescription treatment was achieved by using the SFC data (plus previous data), and showed significative differences when compared to treatment proposed using empirical data ( $p=0.001$ for clinician 1 , and $p=0.016$ for clinician 2); with this information only a $1.4 \%$ of the antimicrobial therapies selected by the two clinical researchers were inappropriate (Table 2).

These results indicated that the SFC was useful as a complemented the MALDI-TOF information. The SFC provided data regarding the susceptibility to the third-generation cephalosporins in $84.6 \%$ of the cases of monomicrobial bacteremia, and in $77.8 \%$ of the polymicrobial ones (Table 3a); and carbapenems resistance in $93.8 \%$ and $88.8 \%$ of the cases (Table 3b). 


\begin{tabular}{|c|c|c|}
\hline $\begin{array}{l}\text { Anti } \\
\text { clini }\end{array}$ & $\begin{array}{l}\text { obial prescription and treatr } \\
\text { s. The treatments of both cli }\end{array}$ & $\begin{array}{l}\text { anges proposed by the } \\
\text { were statistically compared. }\end{array}$ \\
\hline Clinical situation & Clinician 1 & Clinician 2 \\
\hline \multirow[t]{2}{*}{ Empirical treatment } & Carbapenem: 22 (29.7\%) & Carbapenem: 37 (50\%) \\
\hline & Combined treatment: 23 (31.1\%) & Combined treatment: 28 (37.8 \%) \\
\hline \multirow[t]{8}{*}{ Treatment after Gram } & Carbapenem: 22 (29.7\%) & Carbapenem: 43 (58.1 \%) \\
\hline & Combined treatment: $7(9.4 \%)^{\text {a }}$ & Combined treatment: $12(16.2 \%)^{a}$ \\
\hline & Treatment change & Treatment change \\
\hline & Escalation: $1(1.3 \%)$ & Escalation: $0(0 \%)$ \\
\hline & De-escalation: 19 (25.7\%) & De-escalation: $22(29.7 \%)$ \\
\hline & Antibiotic change: 2 (2.7\%) & Antibiotic change: 7 (9.5\%) \\
\hline & Carbapenem de-escalated: 0 ( $0 \%)$ & Carbapenem de-escalated: $0(0 \%)$ \\
\hline & Carbapenem scheduled: $0(0 \%)$ & Carbapenem scheduled: 6 (8.1\%) \\
\hline \multirow[t]{8}{*}{ Treatment after MALDI TOF } & Carbapenem: 25 (33.8 \%) & Carbapenem: 42 (56.7\%) \\
\hline & Combined treatment: $3(4.1 \%)^{b}$ & Combined treatment: $5(6.7 \%)^{b}$ \\
\hline & Treatment change & Treatment change \\
\hline & Escalation: $0(0 \%)$ & Escalation: $1(1.3 \%)$ \\
\hline & De-escalation: 3 (4.1 \%) & De-escalation: 7 (9.5 \%) \\
\hline & Antibiotic change: 13 (17.6 \%) & Antibiotic change: 26 (35.1\%) \\
\hline & Carbapenem de-escalated: (1.3\%) & Carbapenem de-escalated: 4 (5.4\%) \\
\hline & Carbapenem scheduled: 7 (9.4\%) & Carbapenem scheduled: 3 (4.1\%) \\
\hline \multirow[t]{8}{*}{ Treatment after SFC } & Carbapenem: 14 (18.9\%) & Carbapenem: $12(16.2 \%)^{b}$ \\
\hline & Combined treatment: $9(12.1 \%)^{a}$ & Combined treatment: $3(4.1 \%)^{b}$ \\
\hline & Treatment change & Treatment change \\
\hline & Escalation: $5(6.7 \%)$ & Escalation: $1(1.3 \%)$ \\
\hline & De-escalation: 0 (0 \%) & De-escalation: 3 (4.1 \%) \\
\hline & Antibiotic change: 26 (35.1\%) & Antibiotic change: 40 (54.1\%) \\
\hline & Carbapenem de-escalated: 17 (22.9\%) & Carbapenem de-escalated: 32 (43.2 \%) \\
\hline & Carbapenem scheduled: 3 (4.1\%) & Carbapenem scheduled: 2 (2.7 \%) \\
\hline \multirow[t]{8}{*}{ Treatment after cultures } & Carbapenem: $14(18.9 \%)$ & Carbapenem: 13 (17.6\%) \\
\hline & Combined treatment: $8(10.8 \%)$ & Combined treatment: 3 (4.1 \%) \\
\hline & Treatment change & Treatment change \\
\hline & Escalation: 0 (0 \%) & Escalation: $2(2.7 \%)$ \\
\hline & De- escalation: 1 (1.3\%) & De- Escalation: 0 (0\%) \\
\hline & Antibiotic change: 5 (6.7\%) & Antibiotic change: 3 (4.1\%) \\
\hline & Carbapenem de-escalated: 1 (1.3\%) & Carbapenem de-escalated: $0(0 \%)$ \\
\hline & Carbapenem scheduled: 1 (1.3\%) & Carbapenem scheduled: 1 (1.3\%) \\
\hline
\end{tabular}

a indicates $p<0.05{ }^{b}{ }^{\text {indicates }} p<0.0001$. SFC: Sepsis Chip Flow system

\section{DISCUSSION}

In a large majority of the cases the bacteremia treatment must begin empirically because the microbiological techniques at present are not fast enough. However, the increase in the MDR microorganisms often results in inappropriate treatment and the prescription of broad-spectrum drugs or even combinations of several antibiotics $[7,8]$. In the case of incorrect treatments, it is very important to adjust the treatment as soon as possible, in light of the microbiological results, because the data from several studies support that the precocity of an accurate antibiotic treatment is crucial for a good clinical outcome [9-12]. 


\begin{tabular}{|c|c|c|c|c|}
\hline \multirow[t]{2}{*}{ Table 2} & \multicolumn{4}{|c|}{$\begin{array}{l}\text { Correct treatments (active and optimum) were scheduled after receiving } \\
\text { the results from the different diagnostic tests, taking the reference as the } \\
\text { culture data and antimicrobial susceptibility of the microorganism. }\end{array}$} \\
\hline & Empirical treatment & Gram & MALDI-TOF & SFC \\
\hline Clinician 1 & $62 / 74(83.8 \%)$ & $64 / 74(86.5 \%)$ & $66 / 74(89.2 \%)$ & $73 / 74(98.6 \%)^{a}$ \\
\hline Clinician 2 & $66 / 74(89.1 \%)$ & $68 / 74(91.9 \%)$ & 71/74 (95.9\%) & $73 / 74(98.6 \%)^{a}$ \\
\hline
\end{tabular}

aindicates $p<0.05$. SFC: Sepsis Chip Flow system

\begin{tabular}{l|l} 
Table 3a & Evaluation of the SFC in bacteremia caused by a single microorganism.
\end{tabular}

\begin{tabular}{|c|c|c|c|}
\hline Microorganism & Identification ${ }^{\mathrm{a}}$ & Resistance detection to cephalosporins 3rd (ESBL) & Resistance detection to carbapenems (carbapenemases) \\
\hline Escherichia coli $(n=38)$ & Right & (38/38) 100\% & (38/38) 100\% \\
\hline Klebsiella pneumoniae $(n=9)$ & Right & $(9 / 9) 100 \%$ & $(9 / 9) 100 \%$ \\
\hline Klebsiella oxytoca $(\mathrm{n}=4)$ & Partial) & $(4 / 4) 100 \%$ & $(4 / 4) 100 \%$ \\
\hline Proteus mirabilis $(\mathrm{n}=2)$ & Partial & $(2 / 2) 100 \%$ & (2/2) $100 \%$ \\
\hline Enterobacter cloacae $(n=2)$ & Partial & $(0 / 2) 0 \%$ & $(2 / 2) 100 \%$ \\
\hline Stenotrophomonas maltophilia $(\mathrm{n}=2)$ & Right & $(0 / 2) 0 \%$ & $(0 / 2) 0 \%$ \\
\hline Serratia marcescens $(n=2)$ & Partial & $(1 / 2) 50 \%$ & $(2 / 2) 100 \%$ \\
\hline Achromobacter xyloxosidans $(n=1)$ & No identification & $(0 / 1) 0 \%$ & $(1 / 1) 100 \%$ \\
\hline Citrobacter koseri $(n=1)$ & Partial & $(1 / 1) 100 \%$ & $(1 / 1) 100 \%$ \\
\hline Bacteroides thetaiotamicon $(n=1)$ & No identification & $(0 / 1) 0 \%$ & $(1 / 1) 100 \%$ \\
\hline Campylobacter jejuni $(\mathrm{n}=1)$ & No identification & $(0 / 1) 0 \%$ & $(1 / 1) 100 \%$ \\
\hline Acinetobacter baumannii $(n=1)$ & Right & $(0 / 1) 0 \%$ & $(1 / 1) 100 \%$ \\
\hline Pseudomonas aeruginosa $(n=1)$ & Right & $(0 / 1) 0 \%$ & $(1 / 1) 100 \%$ \\
\hline \multirow[t]{3}{*}{ TOTAL $(n=65)$} & Right: 51 (78.5\%) & Sensibility ESBL: 100\% & Sensibility: 64/65 (98.5\%) \\
\hline & Partial: 13 (20\%) & Global data: $55 / 65(84.6 \%)$ & \\
\hline & 0 identification: 3 (4.6\%) & & \\
\hline
\end{tabular}

SFC: Sepsis Chip Flow system; ESBL: extended-spectrum beta-lactamase

aRight: Identification was made correctly: species and gender; Partial: Only the presence of an enterobacteria was identified. The genus and species were unknown; No identification: The identification of the microorganism was not achieved

Regarding the clinical usefulness of the different techniques assessed in this study, it is highlighted that, as had been repeatedly reported, their data are very helpful when a multidisciplinary group with the capability of using them to modify the empirical treatments early (in hours) is involved. The data provided by the cultures are usually available late (24-48 hours) [13-16].

In this study, the efficacy of several techniques were analyzed in a combined manner. Some techniques provided information regarding only the etiology of the infection, while others also reported the antimicrobial susceptibility of the microorganism involved. The results revealed that their data were complementary: Gram stain and MALDI-TOF significantly decreased the combined treatments, while the SFC facilitated a reduction in the use of carbapenems.
These data also confirmed the accuracy of the SFC in identifying the BGN and resistance markers in BSI. Moreover, the combination of MALDI-TOF information and the data provided by this novelty system, SFC, provides a potential reduction in the times to prescribe both effective and optimal antibiotic therapies in the treatment of BGN-BSI. This new system identifies the commonest BGN pathogens related to $\mathrm{BSI}$, and confirms the data provided by the MALDI-TOF in the inconclusive cases, for example polymicrobial infections. Additionally, SFC provides complementary information on the main mechanisms of resistance to the beta-lactams of these microorganism. It is limited, as it cannot detect resistance to the 3 rd generation cephalosporins due to cAMP overproduction and resistance to the carbapenems by mechanisms other than the production of the carbapenemases. SFC could even 


\begin{tabular}{|c|c|c|c|c|}
\hline Table $3 b$ & \multicolumn{4}{|c|}{ Evaluation of SFC in bacteremia caused by more than one microorganism. } \\
\hline \multicolumn{2}{|l|}{ Microorganism } & Identification ${ }^{\text {a }}$ & Resistance detection to cephalosporins $3^{\text {rd }}$ & Resistance detection to carbapenems \\
\hline \multicolumn{2}{|c|}{$\begin{array}{l}\text { Klebsiella pneumoniae } \\
\text { Streptococcus gallolyticus } \\
\text { Escherichia coli } \\
\text { Klebsiella oxytoca } \\
\text { Enterococcus faecalis }\end{array}$} & $\begin{array}{l}\text { Partial: E. faecalis no identified to species } \\
\text { level }\end{array}$ & Right & Right \\
\hline \multicolumn{2}{|c|}{$\begin{array}{l}\text { Staphylococcus epidermidis } \\
\text { Pseudomonas putida } \\
\text { Stenotrophomonas maltophilia }\end{array}$} & Partial: P. putida no identified & Fail: Resistance of BGN no identified & $\begin{array}{l}\text { Fail: Resistance of S.maltophilia no } \\
\text { identified }\end{array}$ \\
\hline \multicolumn{2}{|c|}{$\begin{array}{l}\text { Escherichia coli } \\
\text { Klebsiella pneumoniae }\end{array}$} & Right & Fail: AMPc no detected & Right \\
\hline \multicolumn{2}{|c|}{$\begin{array}{l}\text { Escherichia coli } \\
\text { Enterococcus faecalis }\end{array}$} & $\begin{array}{c}\text { Partial: E. faecalis no identified to species } \\
\text { level }\end{array}$ & Right & Right \\
\hline \multicolumn{2}{|c|}{$\begin{array}{l}\text { Acinetobacter baumannii, } \\
\text { Enterococcus faecalis }\end{array}$} & $\begin{array}{l}\text { Partial: E. faecalis no identified to species } \\
\text { level. }\end{array}$ & Right & Right \\
\hline \multicolumn{2}{|c|}{ Escherichia coli, Enterobacter asburiae } & $\begin{array}{l}\text { Partial: E. asburiae no identified to } \\
\text { species level. }\end{array}$ & Right & Right \\
\hline \multicolumn{2}{|c|}{$\begin{array}{l}\text { Enterobacter ludwigii, Escherichia coli, } \\
\text { Enterococcus faecalis }\end{array}$} & $\begin{array}{l}\text { Partial: E. ludwigii and E. faecalis no } \\
\text { identified to species level. }\end{array}$ & Right & Right \\
\hline \multicolumn{2}{|c|}{$\begin{array}{l}\text { Escherichia coli, Klebsiella pneumoniae, } \\
\text { Morganella morganii, Streptococcus } \\
\text { gallolyticus }\end{array}$} & $\begin{array}{l}\text { Partial: M. morganii no identified to } \\
\text { species level. }\end{array}$ & Right & Right \\
\hline \multicolumn{2}{|c|}{$\begin{array}{l}\text { Coagulase-negative Staphylococcus } \\
\text { Klebsiella pneumoniae }\end{array}$} & Right & Right & Right \\
\hline \multicolumn{2}{|l|}{ Total } & $\begin{array}{l}\text { Right: } 2 / 9(22.2 \%) \\
\text { Partial } 7 / 9(77.8 \%)\end{array}$ & $\begin{array}{l}\text { Right } 7 / 9(77.8 \%) \\
\text { Partial 1/9 (11.1\%) }\end{array}$ & Right 8/9 (88.8 \%) \\
\hline
\end{tabular}

SFC: Sepsis Chip Flow system; ESBL: extended-spectrum beta-lactamase

aRight: Identification was made correctly: species and gender; Partial: Only the presence of an enterobacteria was identified. The genus and species were unknown; No identification: The identification of the microorganism was not achieved

more helpful, in hospitals without the MALDITOF technique, as SFC is a fast method (around 4 hours) to identify the main microorganisms isolated in blood cultures and some of their resistance mechanisms, while the conventional culture and phenotypic study of resistance usually delays 24-48 hours the diagnostic [17].

Therefore, the present study shows the great clinical usefulness of implementing the new SFC system as complement of the fast microbiological techniques established, while confirming that the multidisciplinary groups responsible for the clinical management of these serious and complex pathologies are essential in today's world [18].

\section{FUNDING}

FISABIO Foundation UGP-15-196.

\section{CONFLICTS OF INTEREST}

The authors declare that they have no conflicts of interest

\section{REFERENCES}

1. O'Brien DJ, Gould IM. Maximizing the impact of antimicrobial stewardship. Curr Opin Infect Dis. 2013;26(4):352-8.

2. Kuehn BM. IDSA: Better, Faster Diagnostics for Infectious Diseases Needed to Curb Overtreatment, Antibiotic Resistance. JAMA. 2013;310(22):2385.

3. Hagiwara D, Sato K, Miyazaki M, Kamada M, Moriwaki N, Nakano T, et al. The Impact of Earlier Intervention by an Antimicrobial Stewardship Team for Specific Antimicrobials in a Single Weekly Intervention. Int J Infect Dis. 2018;77:34-39

4. Wolk DM, Dunne WM. New Technologies in Clinical Microbiology. J Clin Microbiol. 2011;49(9 Supplement):S62-7. 
5. Ruiz-Aragón J, Ballestero-Téllez $M$, Gutiérrez-Gutiérrez $B$, de Cueto $M$, Rodríguez-Baño J, Pascual Á. Direct bacterial identification from positive blood cultures using matrix-assisted laser desorption/ionization time-of-flight (MALDI-TOF) mass spectrometry: A systematic review and meta-analysis. Enferm Infecc Microbiol Clin. 2018;36(8):484-92.

6. Galiana A, Coy J, Gimeno A, Guzman NM, Rosales F, Merino E, et al. Evaluation of the Sepsis Flow Chip assay for the diagnosis of blood infections. Chang Y-F, editor. PLoS One. 2017;12(5):e0177627.

7. Carrara E, Pfeffer I, Zusman O, Leibovici L, Paul M. Determinants of inappropriate empirical antibiotic treatment: systematic review and meta-analysis. Int J Antimicrob Agents. 2018;51(4):548-53.

8. Nimmich EB, Bookstaver PB, Kohn J, Justo JA, Hammer KL, Albrecht $H_{1}$ et al. Development of Institutional Guidelines for Management of Gram-Negative Bloodstream Infections: Incorporating Local Evidence. Hosp Pharm. 2017;52(10):691-7.

9. Mwaigwisya S, Assiri RAM, O'Grady J. Emerging commercial molecular tests for the diagnosis of bloodstream infection. Expert Rev Mol Diagn. 2015;15(5):681-92.

10. Raman G, Avendano E, Berger S, Menon V. Appropriate initial antibiotic therapy in hospitalized patients with gram-negative infections: systematic review and meta-analysis. BMC Infect Dis. 2015;15(1):395.

11. Pulido MR, Garcia-Quintanilla M, Martin-Pena R, Cisneros JM, McConnell MJ. Progress on the development of rapid methods for antimicrobial susceptibility testing. J Antimicrob Chemother. 2013;68(12):2710-7.

12. Merino $E$, Caro E, Ramos JR, Boix V, Gimeno A, Rodriguez JC, et al. Impact of a stewardship program on bacteraemia in adult inpatients. Rev Esp Quimioter. 2017;30(4):257-63.

13. Sothoron C, Ferreira J, Guzman N, Aldridge P, McCarter YS, Jankowski CA. A Stewardship Approach To Optimize Antimicrobial Therapy through Use of a Rapid Microarray Assay on Blood Cultures Positive for Gram-Negative Bacteria. Munson E, editor. J Clin Microbiol. 2015;53(11):3627-9.

14. Perez KK, Olsen RJ, Musick WL, Cernoch PL, Davis JR, Peterson LE, et al. Integrating rapid diagnostics and antimicrobial stewardship improves outcomes in patients with antibiotic-resistant Gram-negative bacteremia. J Infect. 2014;69(3):216-25.

15. Delport JA, Strikwerda A, Armstrong A, Schaus D, John M. MALDI-ToF short incubation identification from blood cultures is associated with reduced length of hospitalization and a decrease in bacteremia associated mortality. Eur J Clin Microbiol Infect Dis. 2017;36(7):1181-6.

16. Rivard KR, Athans V, Lam SW, Gordon SM, Procop GW, Richter SS, et al. Impact of antimicrobial stewardship and rapid microarray testing on patients with Gram-negative bacteremia. Eur J Clin Microbiol Infect Dis. 2017;36(10):1879-87.

17. Cantón R, Gómez G. de la Pedrosa E. Impacto económico de los métodos de diagnóstico rápido en Microbiología Clínica: precio de la prueba o impacto clínico global. Enferm Infecc Microbiol Clin. 2017;35(10):659-66.

18. Dik J-WH, Poelman R, Friedrich AW, Panday PN, Lo-Ten-Foe JR,
Assen S van, et al. An integrated stewardship model: antimicrobial, infection prevention and diagnostic (AID). Future Microbiol. 2016;11(1):93-102. 